DOI https://doi.org/10.30525/978-9934-26-075-9-9

\title{
EVALUATION OF THE IMPACT OF THE COVID-19 PANDEMIC ON THE EDUCATIONAL PROCESS OF MEDICAL INTERNS
}

\author{
Hechko M. M. \\ Assistant at the Department of therapy and family medicine \\ Uzhgorod National University \\ Uzhgorod, Ukraine \\ Kurakh A. V. \\ Assistant at the Department of therapy and family medicine \\ Uzhgorod National University \\ Uzhgorod, Ukraine \\ Hechko K. A. \\ Assistant at the Department of therapy and family medicine \\ Uzhgorod National University \\ Uzhgorod, Ukraine \\ Rumaneh W. W. S. \\ Assistant at the Department of surgery, $t$ \\ raumatology, orthopedics and phthisiology \\ Sumy State University \\ Sumy, Ukraine
}

Introduction. 2020 has become a challenge for many aspects of human life. In addition to obvious risks to life and health of the population, as well as the stability of the world economy, the COVID-19 pandemic has greatly affected learning processes in educational institutions [1,2].

Medical education was especially affected, because for future physicians, physical and lingual contact with the patient plays a key role in the educational process. But in the context of a global pandemic, this contact facilitates the spread of the disease, which is dangerous both for the student and the patient. Furthermore, not every intern feels ready to face COVID-19 [3]. Up to this day, educators mostly considered the possibility of mixed online and traditional (face-to-face) training, without switching to continuous distance learning. Online eLearning was deemed equivalent to and perhaps even more effective than traditional learning in terms of knowledge and skills gained [4]. With technological development, better access to the Internet and the spread of principals of Continuous medical education (CME), distance learning took up its niche in line with traditional forms of medical education [5]. To optimize this process, it is necessary to take into account the specifics of the 
pedagogical process on online platforms, medical educators need to understand and adapt the approach to learning to contemporary requirements, as well as improve the attitude of teachers to distance learning [6].

Despite its usefulness in facilitating access to knowledge and perfecting of practical skill development, it remains challenging for teachers to get accustomed to these new forms of teaching, taking into consideration the dire need (social distancing) and a requirement for learning new skills and adapting to technological conditions. How teachers perceive distance education in the context of medicine, also plays a great role. Medical education without faceto-face contact feels absurd to many seasoned educators. Despite this, we are facing a scenario, where online learning prevails over traditional forms.

The aim: to assess the impact of quarantine restrictions related to the COVID-19 pandemic on the educational activities of educators and the educational process of interns in the first year of study.

Materials and methods: in order to assess the quality of education in the second semester of the 2019/2020 academic year, an online survey was conducted among faculty of post-graduate education (FPE) teachers $(n=44)$ and interns of the first year of study $(n=88)$ using Google forms. The link to the form was sent separately to teachers and interns. The teacher survey consisted of 10 questions related to the organization of distance learning and the instruments for its realization. The questionnaire for interns contained 16 questions divided into three blocks. The first block contained general questions and questions about the organization of the educational process, the second and the third - regarded parts of the training conducted on the faculty and medical facility respectively. Customer Satisfaction Index (CSI) was used for the assessment. Both forms did not collect personal data of the respondents. The questions were divided into three types of groups. The first group only close-ended questions with the answers being either "yes" or "no". In the second group of questions, we asked to evaluate several aspects of the organization of the educational process in a scale from 0 to 10. The third group contained open-ended questions about opportunities to improve the quality of education. Their responses were evaluated using the Customer Satisfaction Index (CSI) and the Net Score Promoters (NSP).

Results. We analyzed the answers provided by teachers, which related to the use of basic tools for distance learning - MOODLE, Google Meet and others. As a result, it was found that $27.3 \%$ of the pedagogical staff of the faculty use other services besides MOODLE and Google Meet, including Viber, Google Classroom, Zoom and Skype to organize the educational process and communication. In addition, about $80 \%$ of respondents indicated that it would be reasonable to conduct additional training on the functionality of the distance learning platform.

Taking into account the importance of training future doctors at the patient's bedside, we assessed the degree of restriction of access to the clinic 38 
faced by interns, due to the introduction of quarantine and the cancellation of planned outpatient appointments and hospitalizations. According to the survey, it was found that $22.7 \%$ and $28.4 \%$ of interns faced limited access to patients in the clinic, on faculty and medical facility training respectively. This situation was most common among interns of therapeutic specialties. Thus, almost one in every four interns had the opportunity to study only remotely.

Fig. 1 Have you encountered restrictions on access to patients in the clinic?

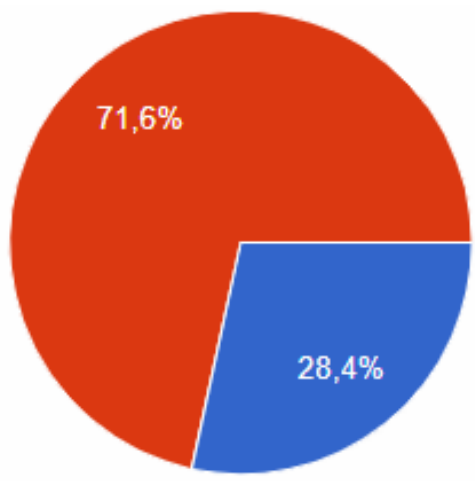

A. Faculty

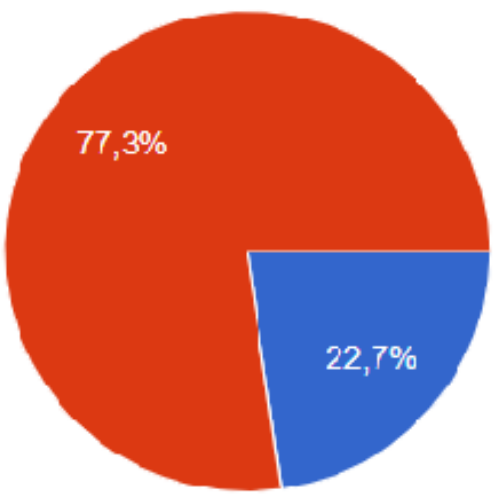

B. Medical facility

As for the educational process, the reason for this is the introduction of anti-epidemic measures and the transformation of part of healthcare institutions to be able to treat COVID-19 patients and work only with urgent cases. And this situation is most painfully reflected in the training of interns of therapeutic specialties.

Assessing the quality of online learning, respondents noted a better level of classes on Google Meet (Fig. 2; average score 6.77 out of 10; NSP index 3.45) compared to MOODLE (Fig. 3; average score 6.09 out of 10; NSP index -26.44). However, $17.0 \%$ pointed out the fact that they did not have online classes in real time. The overall assessment of the current state of internship training is low (Fig. 4; the average score is 5.95 out of 10; the NSP index is 26.44). To the question "What do you think should be changed in the educational process in these conditions", the answers were as follows: $31.4 \%$ were for returning to offline learning as much as possible; $23.3 \%$ would reduce the cost; $23.3 \%$ expressed their support for improving the quality of educational materials and online classes. At the same time, $22.1 \%$ believe that the quality of education is sufficient, especially considering the crisis we are facing today. 


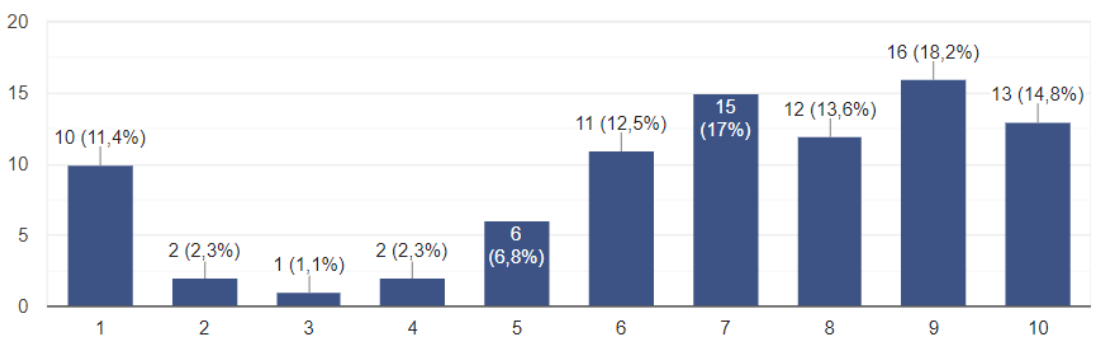

Fig. 2. Please rate on a scale from 1 to 10 the quality of classes by videoconferencing, where 1 - "Their broadcasting football", 10 - "I will subscribe to this podcast"

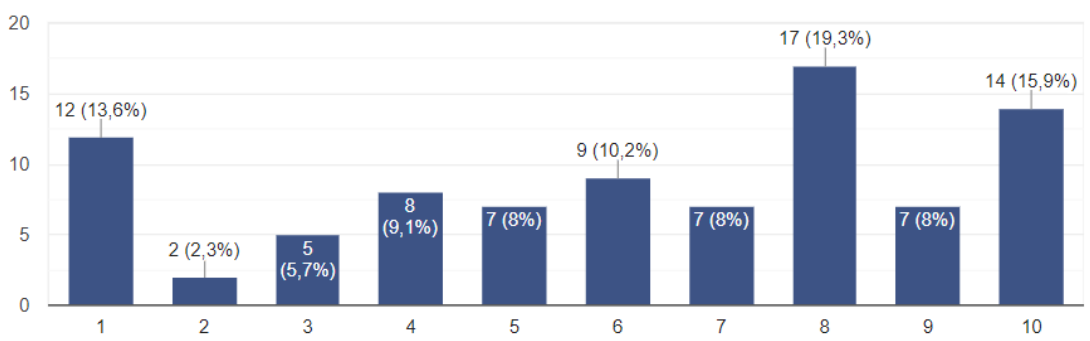

Fig. 3. Please evaluate on a scale of 1 to 10 quality of educational materials on the e-learning platform of UzhNU (MOODLE), where 1 - " What is this?", 10 - "I need access to them forever!

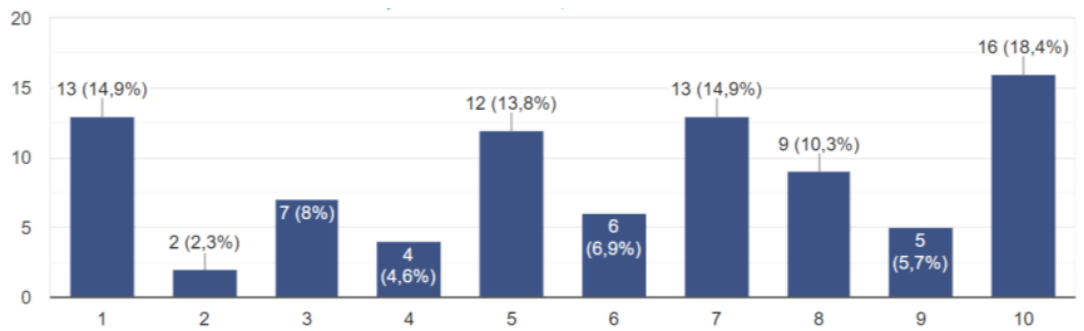

Fig. 4. Please evaluate on a scale of 1 to 10 the overall quality of study at internship, where 1 - "@\#\%^\&", 10 - "Without this stage it is impossible to become a specialist"

Conclusion. Based on the results and experience of online learning in the second semester of the academic year, we state that this type of organization of the educational process is an adequate addition to traditional training, but 40 
cannot serve as a complete replacement in the preparation of future doctors. Adequate training of specialists in the field of health is possible only when conducting classes and training in healthcare institutions. At the same time, the development and progress of digital learning materials and online forms of education opens up new opportunities for the continuous professional improvement of doctors and facilitation of networking in the professional environment.

The COVID-19 pandemic has given impetus to a significant expansion of distance learning opportunities.

\section{References:}

1. Aristovnik A., Keržič D., Ravšelj D., et al. Impacts of the COVID-19 Pandemic on Life of Higher Education Students: A Global Perspective. Sustainability. 2020. Vol. 12, No. 20. P. 8438.

2. Emanuel E. J. The Inevitable Reimagining of Medical Education. JAMA. 2020. Vol. 323, No. 12. P. 1127-1128.

3. Moreira M. R. C., Aquino R. de F., Barros L. L., et al. Do medical interns feel prepared to work in the COVID-19 pandemic? Revista da AssociaÃß̃̃ lpoundso MÃlcopyrightdica Brasileira. 2020. Vol. 66. P. 973-978.

4. George P. P., Papachristou N., Belisario J. M., et al. Online eLearning for undergraduates in health professions: A systematic review of the impact on knowledge, skills, attitudes and satisfaction. Journal of global health. 2014. Vol. 4, No. 1. P. 10406.

5. Masic I. E-learning as new method of medical education. Acta informatica medica: AIM : journal of the Society for Medical Informatics of Bosnia \& Herzegovina: casopis Drustva za medicinsku informatiku BiH. 2008. Vol. 16, No. 2. P. 102-117.

6. O'Doherty D., Dromey M., Lougheed J., et al. Barriers and solutions to online learning in medical education - an integrative review. BMC medical education. 2018. Vol. 18, No. 1. P. 130. 